\title{
Case histories of infectious disease management in developing countries: Phnom Penh and Kabul
}

\author{
As doenças infecciosas nos países em \\ desenvolvimento: Phnom Penh e Cabul
}

Florian H. Pilsczek ${ }^{1}$

\begin{abstract}
Healthcare in developing countries is affected by severe poverty, political instability and diseases that may be of lesser importance in industrialized countries. The aim of this paper was to present two cases and histories of physicians working in hospitals in developing countries and to discuss the opportunities for clinical investigation and collaboration. Cases of patients in Phnom Penh, Cambodia, with histoplasmosis, cryptococcal meningitis, crusted scabies, cerebral lesions and human immunodeficiency virus and of patients in Kabul, Afghanistan, with liver cirrhosis, nephrotic syndrome and facial ulcer are discussed. Greater developmental support is required from industrialized nations, and mutually beneficial cooperation is possible since similar clinical problems exist on both sides (e.g. opportunistic cardiovascular infections). Examples for possible support of hospital medicine include physician interchange visits with defined objectives (e.g. infection control or echocardiography training) and collaboration with clinical investigations and projects developed locally (e.g. epidemiology of cardiovascular diseases or nosocomial bloodborne infections).
\end{abstract}

Key-words: Developing countries. Infectious diseases. Collaboration. Cambodia. Afghanistan.

\section{RESUMO}

A assistência à saúde em países em desenvolvimento é afetada pela pobreza extrema, instabilidade política e doenças que podem ter menor importância em países industrializados. 0 objetivo deste trabalho foi apresentar dois casos e histórias de médicos que trabalham em hospitais de países em desenvolvimento e discutir as oportunidades de investigação clínica e cooperação. São discutidos casos de pacientes em Phnom Penh, no Camboja, com histoplasmose, meningite criptocócica, sarna, lesões cerebrais e vírus da imunodeficiência humana, e de pacientes em Kabul, no Afeganistão, com cirrose hepática, síndrome nefrótica e úlcera facial. Maior apoio ao desenvolvimento por parte dos países desenvolvidos é essencial, e uma cooperação mutuamente benéfica é possível, visto que problemas clínicos similares existem em ambos os lados (p. ex. infecções cardiovasculares oportunistas). Exemplos para possível apoio à medicina hospitalar incluem intercâmbio de médicos para visitas com objetivos definidos (p. ex. controle de infecção ou treinamento em ecocardiografia) e colaboração com investigações clínicas e projetos desenvolvidos localmente (p. ex. epidemiologia de doenças cardiovasculares ou infecções hospitalares causadas por via sanguínea).

Palavras-chaves: Países em desenvolvimento. Doenças infecciosas. Colaboração. Camboja. Afeganistão.

Healthcare in developing countries is affected by severe poverty, political instability and diseases that may be of lesser importance in industrialized nations ${ }^{1413}$. On the other hand, healthcare in hospitals in industrialized nations comes up against multiple morbidities in immunocompromised hosts that, for example, may be due to chronic renal failure, immunosuppressive medication, fungal infections in organ transplant patients or during cancer treatment, or multidrug-resistant bacteria such as methicillin-resistant Staphylococcus aureus (MRSA) ${ }^{22}$.

The purpose of this report was to describe hospital clinical medicine in the developing countries of Cambodia (City of Phnom

1. Division of Infectious Diseases, Department of Medicine, University of Calgary, Calgary T2N 4N1, Alberta, Canada.

Address to: Dr. Florian Pilsczek. Immunology Research Group, Dept of Physiology and Biophysics, University of Calgary. Calgary T2N 4N1, Alberta, Canada.

Tel: 403 220-7658; Fax: 403 270-7516.

e-mail: f.h.pilsczek@gmail.com

Received in $08 / 02 / 2009$

Accepted in 15/09/2009
Penh) and Afghanistan (City of Kabul), based on clinical case histories, and to discuss opportunities for clinical and research collaboration. The case histories presented include patients with histoplasmosis, cryptococcal meningitis, crusted scabies, cerebral mass lesions, human immunodeficiency virus (HIV), liver cirrhosis, nephrotic syndrome and facial ulcers. Increased support for hospital healthcare in developing countries is required from industrialized nations, and mutually beneficial cooperation is possible since similar clinical problems exist on both sides (e.g. opportunistic infections or liver disease).

\section{MATERIAL AND METHODS}

The case histories and clinical observations for this report were collected at hospitals in Phnom Penh, Cambodia (Khmer Soviet Friendship Hospital), and Kabul, Afghanistan (Ali Abad Hospital) during discussions with healthcare workers and patients and after reviewing the medical records. Photographs 
were obtained with a digital camera (Canon 530A). The study was approved by both hospitals (Khmer Soviet Friendship Hospital and Ali Abad Hospital). Verbal consent was obtained before taking clinical photographs.

\section{RESULTS AND DISCUSSION}

Phnom Penh. A 42-year-old male Khmer patient with acquired immunodeficiency syndrome (AIDS) that was being treated with lamivudine, stavudine and efavirenz was admitted with a generalized papular skin rash, weight loss and fever (Figure 1A, Figure 1B and Figure 1C). Blood cultures did not show any growth of fungi or mycobacteria, while fungal culturing of a skin biopsy was positive for Histoplasma capsulatum. A test for serum cryptococcal antigen was negative and lumbar puncture and the serum VDRL (venereal disease research laboratory) test were not performed. He was treated with intravenous amphotericin B for disseminated histoplasmosis. Other fungal infectious causes of generalized skin rash in HIV-infected patients in Cambodia include Cryptococcus neoformans and Penicillium marneffe ${ }^{2}$.

A 43-year-old male Khmer patient with AIDS was admitted with headache. Cryptococcal meningitis was diagnosed based on positive serum and cerebrospinal fluid (CSF) cryptococcal antigen and CSF fungal culture (Figure 2A). He was treated with intravenous amphotericin B and, after an initially poor clinical response, flucytosine was added. Serum flucytosine testing because of the risk of high levels of bone marrow suppression was not available $^{17}$. This patient required repeated lumbar punctures to treat the elevated intracranial pressure that was causing the headache (Figure 2B). Controlling elevated CSF pressure by means of lumbar drainage improves the symptoms of and outcome from cryptococcal meningitis 9 .

A number of patients were seen who required repeated lumbar punctures for elevated CSF pressure. For some patients, lumbar drains were placed (Figure 2C) by the physicians as a bedside procedure. Ventriculoperitoneal shunts were not used ${ }^{23}$. On admission to hospital in Cambodia, most patients present with undiagnosed advanced HIV disease and are not taking HIV medication. Coinfection with tuberculosis or cryptococcal meningitis is common. When HIV treatment is started together with other treatments, e.g. for cryptococcal infection, patients frequently deteriorate with decreasing consciousness levels due to immune reconstitution syndrome (IRS). For this reason, clinicians avoid starting HIV therapy in hospital and clinical studies are in progress regarding the time to start antiretroviral treatment among patients with coinfections ${ }^{20}$.

A 32-year-old male Khmer soldier with HIV infection and a history of treated tuberculous meningitis was admitted with hemiplegia (Figure 3A and Figure 3B). Examination of cerebrospinal fluid was negative for cryptococcal antigen and the VDRL serological test was negative. Brain imaging using computed tomography showed a single large cerebral lesion (Figure 3C). A number of patients with similar presentations were seen and treated empirically for toxoplasmosis with pyrimethamine and
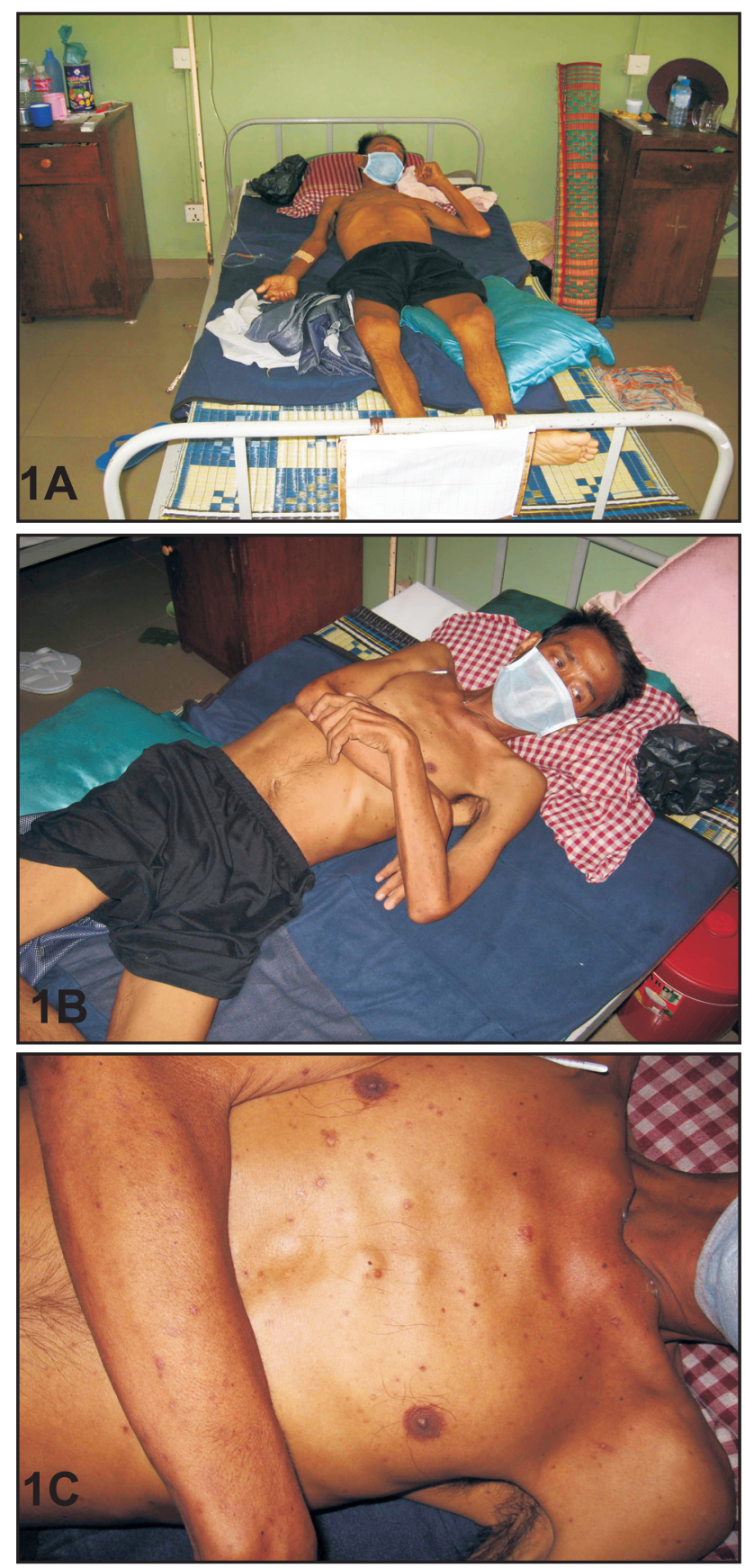

FIGURE 1A-C

Patient with AIDS and disseminated histoplasmosis. This 42-year-old Khmer patient with acquired immunodeficiency syndrome (AIDS) was admitted with a generalized papular skin rash (Images A and B). Fungal culturing of a skin biopsy from the rash (Image C) grew Histoplasma capsulatum and he was treated with intravenous amphotericin B for disseminated histoplasmosis. Other fungal infectious causes of generalized skin rash among HIV-infected patients in Cambodia include Cryptococcus neoformans and Penicillium marneffei.

sulfadoxine. Investigations such as PCR (polymerase chain reaction) on CSF, serological tests for Epstein-Barr virus (EBV), cytomegalovirus (CMV) or JC virus and brain biopsy were not available.

Other possible causes of such lesions include tuberculoma, progressive multifocal leukoencephalopathy (PML), primary CNS (central nervous system) lymphoma and bacterial abscess. Only a few studies have been conducted in Southeast Asia on the 

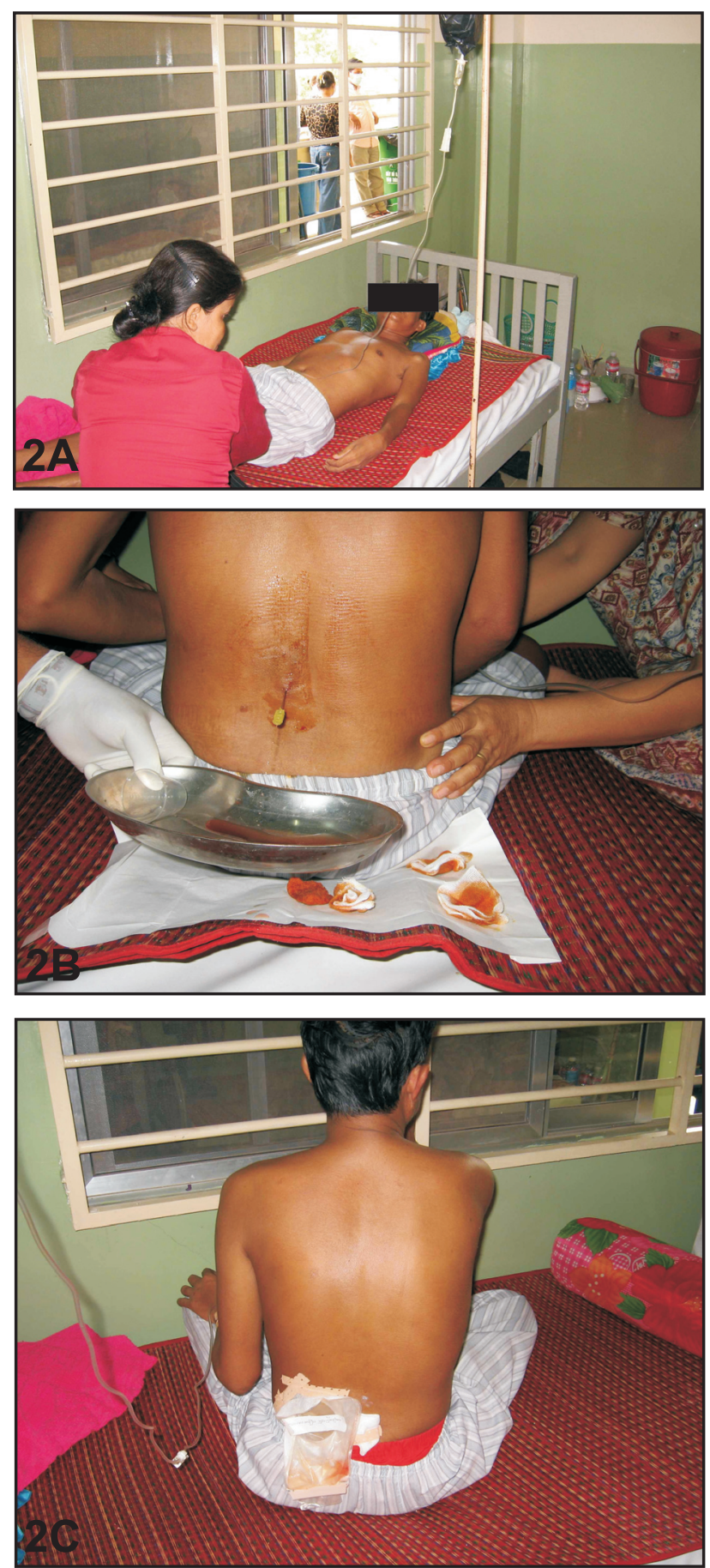

FIGURE 2A-C

Cryptococcal meningitis management with repeated lumbar puncture and lumbar drain. This patient with AIDS and cryptococcal meningitis was treated with intravenous amphotericin B (Image A) and repeated lumbar puncture (Image B). Image B was taken during the lumbar puncture and shows the increased flow of cerebrospinal fluid secondary to increased cerebrospinal fluid pressure. After repeated lumbar punctures, a lumbar drain was inserted by the physician at the bedside (Image C).

frequency of brain involvement with bacteria (e.g. Nocardia species), fungi (e.g. Candida species, Histoplasma capsulatum, Penicillium marneffei), protozoa (e.g. Entamoeba histolytica) or helminths (e.g. Gnathostoma spinigerum) and the management of such situations.

A male Khmer patient with HIV infection was admitted with a generalized rash that had lasted for months (Figure 4A and Figure $\mathbf{4 B}$ ). There was no evidence of any adverse reaction to
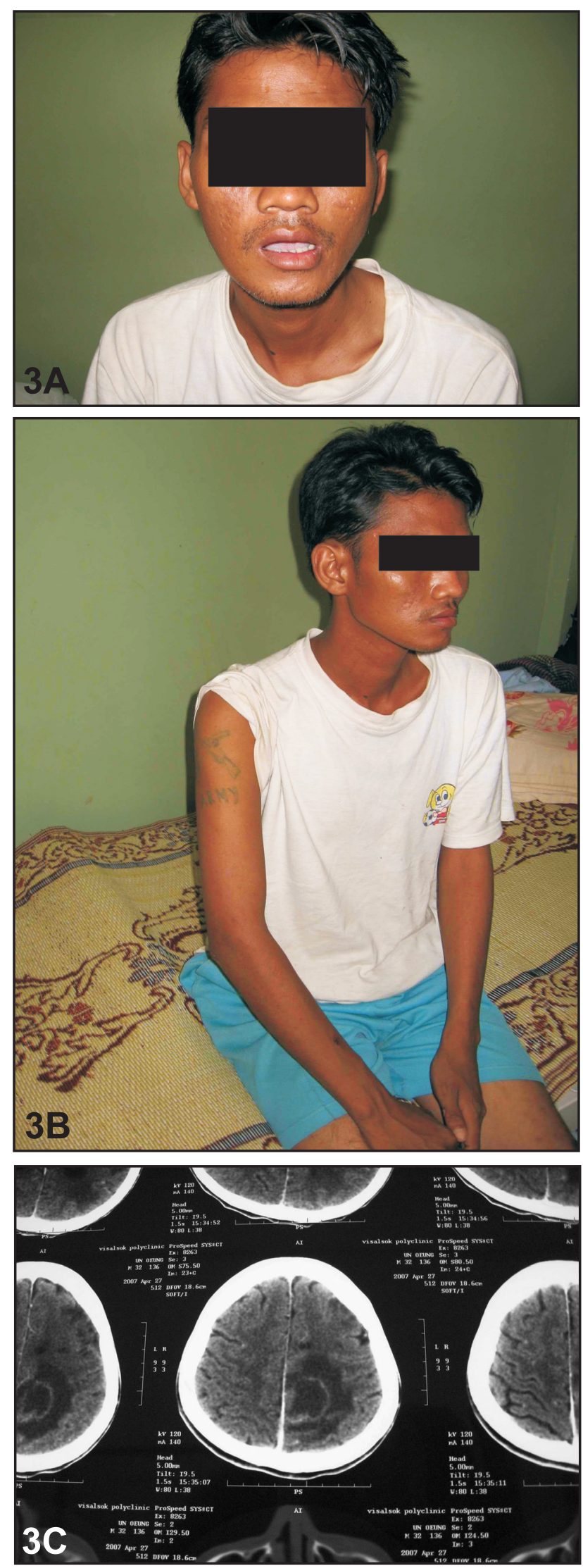

FIGURE 3A-C

Intracerebral lesions in HIV-infected patients. This male Khmer AIDS patient and former soldier with hemiplegia (Image Aand B) was treated empirically for toxoplasmosis with large intracerebral lesions (Image C). A number of patients were seen with a similar presentation. The available diagnostic investigations were limited and few studies on the causes of intracerebral lesions and their management have been conducted in Southeast Asia. 

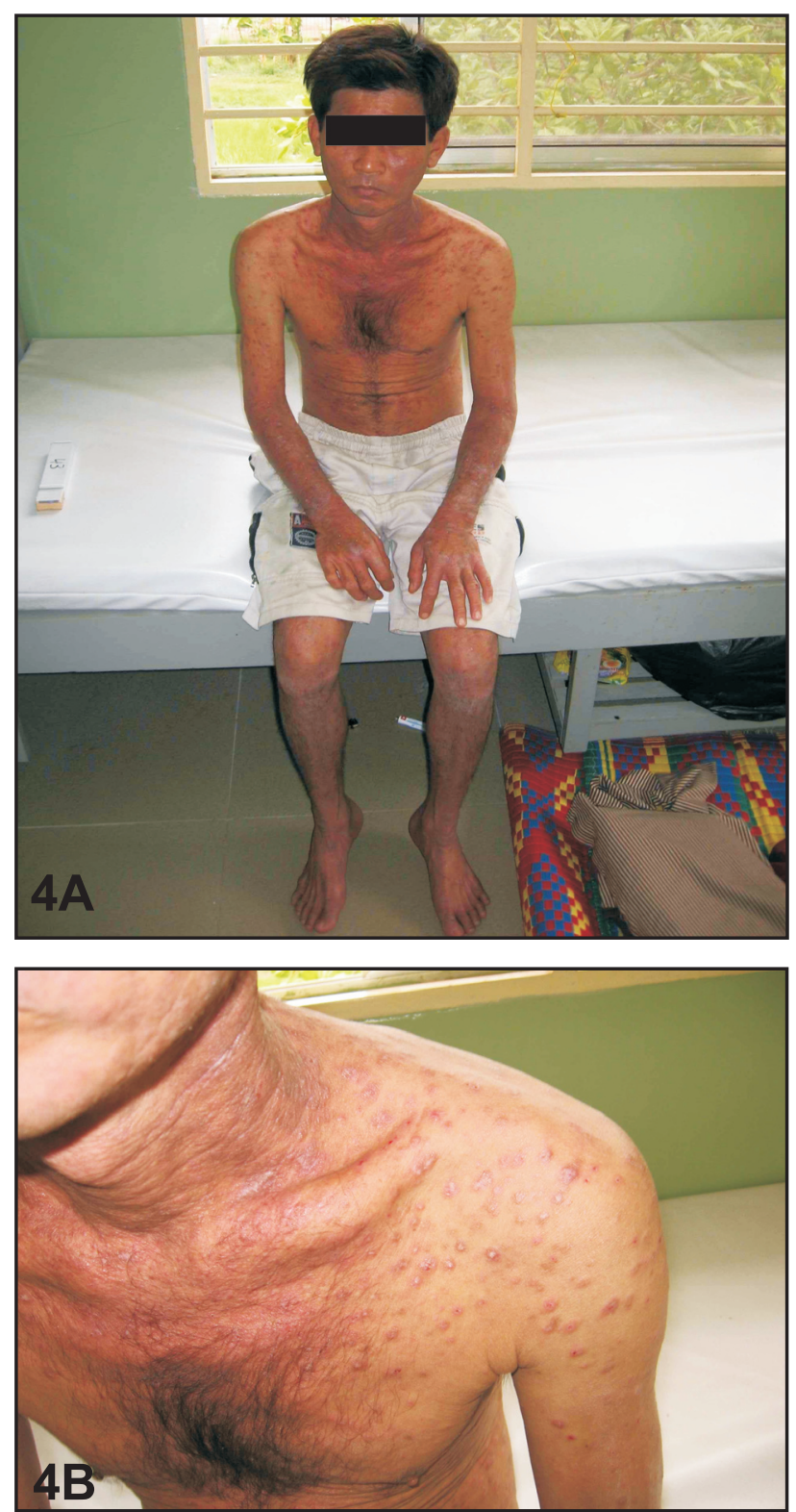

FIGURE 4A-B

Crusted scabies. This male Khmer patient with HIV infection was admitted with a generalized rash that had lasted for months. There was no evidence of any adverse reaction to medication, and serum VDRL was negative. He was treated empirically for crusted scabies with topical scabicides and repeated doses of ivermectin.

his HIV medication, and serum VDRL was negative. Histological analysis on a cutaneous biopsy was inconclusive and he was treated with pyrethrin and ivermectin for Norwegian or crusted scabies.

Different patients with skin rashes associated with antiretroviral therapy were seen, and these rashes were especially associated with nevirapine. This drug is the non-nucleoside reverse transcriptase inhibitor (NNRTI) most frequently used in Cambodia, and efavirenz is not available to most patients due to higher costs. Unlike efavirenz, nevirapine has to be given twice daily and it has greater potential for severe adverse reactions such as hepatotoxicity and rash. It typically causes an erythematous maculopapular rash ${ }^{7}$. Figure 5 shows a female Khmer patient with HIV infection who developed a generalized skin rash that was attributed to treatment with nevirapine. Factors that may increase the side effects from highly active anti-retroviral therapy (HAART) in developing countries include anemia, malnutrition, tuberculosis and advanced HIV disease ${ }^{721}$.

Kabul. A 42-year-old male Afghan patient was admitted with abdominal swelling that had lasted for years (Figure 6). Liver disease had been diagnosed in the past and, because of increasing abdominal swelling over recent years, he had decided to come to the hospital from an outlying province. Because of a positive serum HbsAg test, he was clinically diagnosed with liver cirrhosis with portal hypertension and ascites, probably due to chronic hepatitis $\mathrm{B}$ virus (HBV) infection. He was treated with fluid restriction, diuretic therapy and repeated paracentesis.

No published epidemiological data are available, but from discussions with clinicians, the most common causes of liver cirrhosis in Afghanistan are $\mathrm{HBV}$ and hepatitis C virus (HCV)

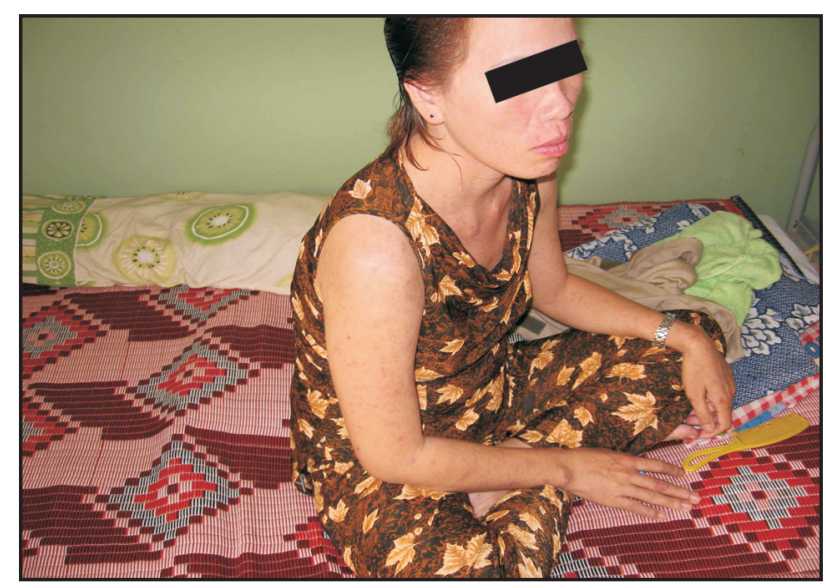

FIGURE 5

Generalized skin rash relating to nevirapine. This female Khmer patient with HIV infection developed a generalized skin rash attributed to treatment with nevirapine. The factors that may increase the frequency of side effects from highly active antiretroviral therapy (HAART) in developing countries include anemia, malnutrition, tuberculosis and advanced HIV disease.

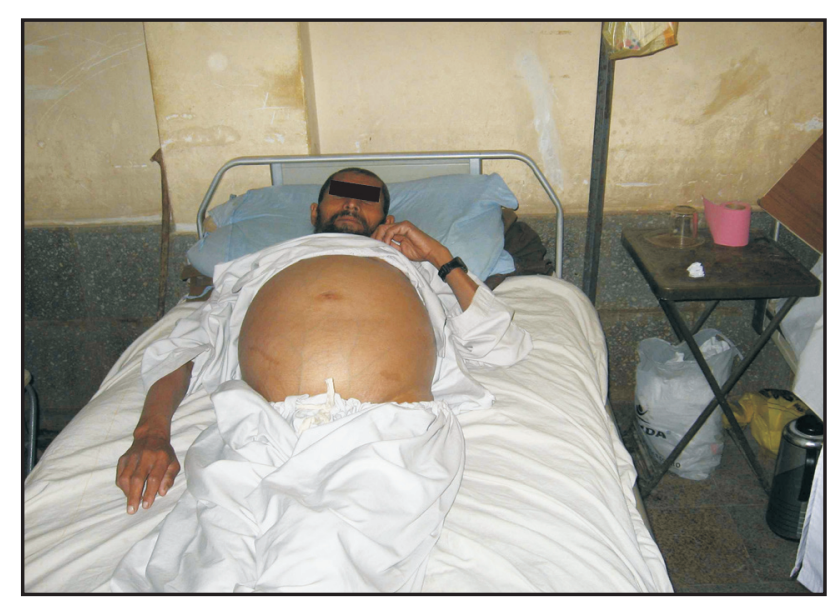

FIGURE 6

Liver cirrhosis and chronic hepatitis. This 42-year-old male Afghan was admitted with increasing abdominal swelling due to liver cirrhosis with portal hypertension. No epidemiological data were available, but from discussions with clinicians, the most common causes of liver cirrhosis in Afghanistan are hepatitis B virus (HBV) and hepatitis $\mathrm{C}$ virus (HCV) infection. An effective vaccine against $\mathrm{HBV}$ is available but not offered as part of any public health program due to limited availability of funding. 
infection. Alcohol is unlikely to be a common cause due to limited availability. The prevalence of serum positive for hepatitis B surface antigen was $8.3 \%$ among Afghan refugees living in Pakistan and $4.1 \%$ among Afghan refugees living in the United States ${ }^{3}$. It is not known how many infections are transmitted through sexual intercourse, unsafe injection practice or other procedures, but it is likely that HBV is frequently acquired perinatally or during early childhood in Afghanistan. An effective vaccine against HBV is available but not offered as part of any public health program due to limited availability of funding.

The above patient is representative of a large number of patients in Afghanistan with complications from chronic hepatitis, including liver cirrhosis and hepatocellular carcinoma. It is likely that $\mathrm{HBV}$ vaccination for children and risk groups would be as effective as found previously elsewhere e.g. in Taiwan or the United States ${ }^{15}$.

A 21-year-old male Afghan patient was admitted with mild legswelling and a history of renal disease five years earlier. Based on normal serum creatinine concentration and proteinuria, nephrotic syndrome was diagnosed and diuretics and steroids were started (Figure 7). Nephrotic syndrome may include membranous glomerulopathy, minimal change disease and focal and segmental glomerulosclerosis, and treatment with corticosteroids may lead to improvement ${ }^{12}$. Treatment with steroids shows no consistent improvement of membranous glomerulopathy, which is associated with certain infections that are prevalent in Afghanistan: HBV, HCV, syphilis, Plasmodium malariae, leprosy, tuberculosis, streptococcal infection, abscess and filariasis.

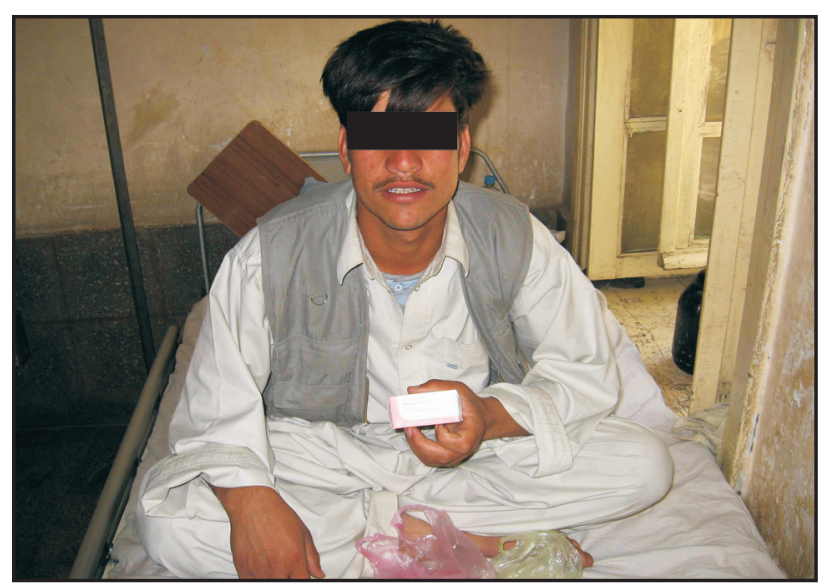

FIGURE 7

Afghan patient with nephrotic syndrome treated with corticosteroids. This 21-year-old male Afghan patient was diagnosed with nephrotic syndrome based on normal serum creatinine concentration and proteinuria. He was treated with oral prednisolone and diuretics for suspected nephrotic syndrome with steroid-responsive glomerular disease.

The use of steroids, for example for nephrotic syndrome in Afghanistan and other developing countries, is limited by higher prevalence of infections such as those due to Mycobacterium tuberculosis, Strongyloides stercoralis, and Leishmania major, which may be latent or undiagnosed and become symptomatic during steroid treatment.
Aliabad Hospital is a teaching hospital of Kabul University, and bedside teaching of medical students and internal medicine residents can be seen in Figure 8. Due to lack of funding and a civil war, the facilities and teaching available are limited. According to discussions with Afghan physicians, improvement could be achieved through professional visits by foreign physicians and surgeons from different specialties and through opportunities for students and doctors to train abroad during electives, residency, fellowship or sabbatical leave.

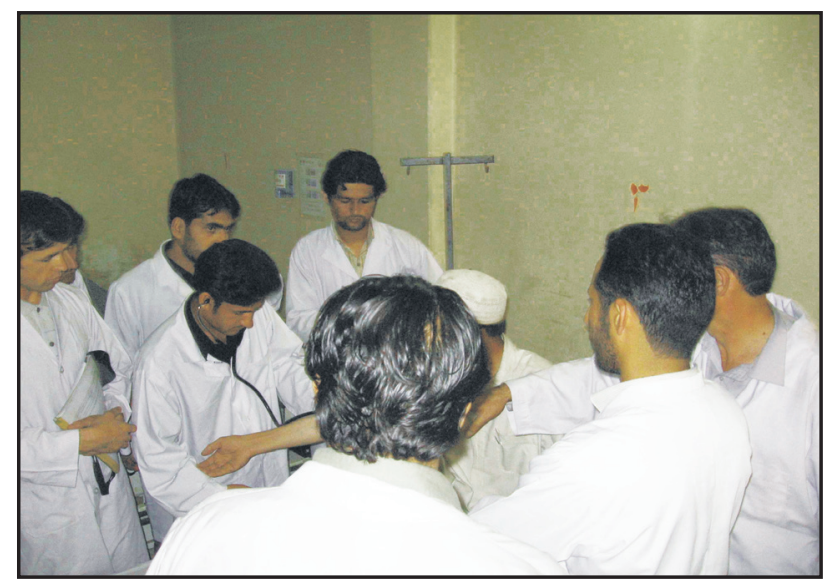

FIGURE 8

Clinical teaching of students and doctors. Afghan medical students and medical residents are shown during bedside teaching. Medical education in Kabul faces major challenges due to social instability and limited resources. According to discussions with Afghan physicians, improvement could be achieved through professional visits by foreign physicians and surgeons from different specialties and opportunities for students and doctors to train abroad during electives, residency, fellowship or sabbatical leave.

The general availability of current medical information through textbooks and the internet was good in Phnom Penh and Kabul. Afghan clinicians and students benefit from exchange visits through improving their proficiency in the English language for medical communication and professional development e.g. in areas such as infection control, HIV prevention, echocardiography, hospital management and procedures (e.g. gastrointestinal endoscopy) ${ }^{13}$.

In Afghanistan, symptoms such as night sweating, poor appetite and weakness are of less diagnostic value. Patients are exposed to a tropical climate with high humidity and may have no access to air conditioning or fans. Night sweating will therefore be present regardless of the illness and is not a useful symptom for chronic infection or malignancy in this setting. If patients are resource-poor or refugees and have inadequate nutritional intake, constitutional symptoms such as weakness, tiredness, malaise and weight loss are of limited diagnostic value ${ }^{8}$.

A 29-year-old Afghan male patient with a facial ulcer and enlarged cervical lymph nodes for one year was seen in Kabul (Figure 9A and Figure 9B). The wound had healed intermittently in the past and had been treated topically with different steroid creams. The possible causes of the facial ulcer included cutaneous leishmaniasis, mycobacterial infection and fungal infection (e.g. sporotrichosis) ${ }^{1}$. 

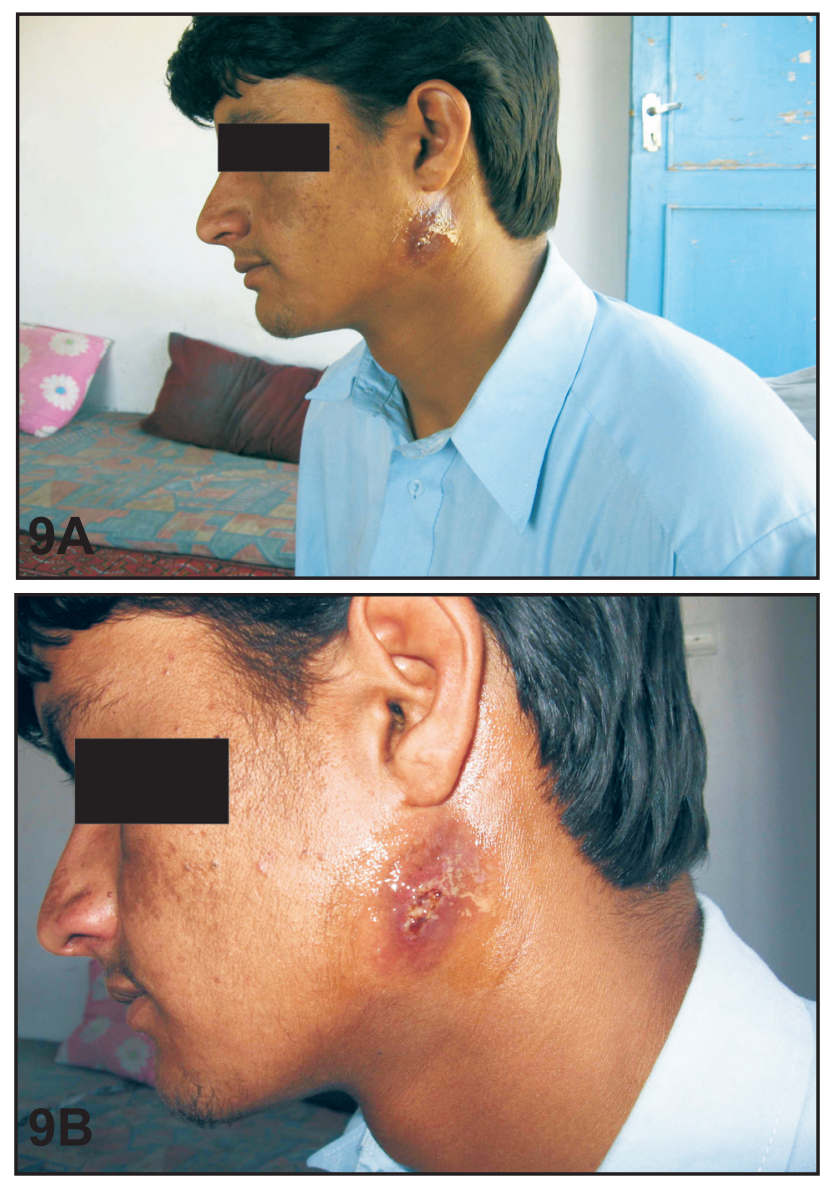

FIGURE 9A-B

Patient with facial ulcer in Kabul, Afghanistan. The image shows a 29-year-old Afghan patient in Kabul with a facial ulcer and enlarged cervical lymph nodes for one year. The wound had healed intermittently in the past and was treated with different steroid creams. The possible causes include cutaneous leishmaniasis, mycobacterial infection and fungal infection (e.g. sporotrichosis)

Kabul, with two million citizens, has a yearly incidence of approximately 67,500 new cases of cutaneous leishmaniasis. Leishmaniasis is transmitted through the bite of infected sandflies, and humans and animals (e.g. dogs) are reservoirs. Poor housing conditions and underfunded public health are likely causes of the high frequency of leishmaniasis in Kabul. Speciation is useful, since Leishmania major and Leishmania tropica (frequent in Kabul) affect mainly the skin and lymphocutaneous tissues, while Leishmania donovani and Leishmania infantum usually involve internal organs such as the liver and spleen ${ }^{16}$.

At public government hospitals in Cambodia and Afghanistan, physicians work from 9:00 am to 12:00 pm. In the afternoon and evening, most physicians work in private clinics. Remuneration through private clinics outside of the hospital is required to meet basic living expenses. Consequently, the time available for hospital patient care and professional education is limited. To improve hospital healthcare, health professionals in both countries need to receive higher remuneration for clinical work at government hospitals.

Physicians in industrialized nations generally rely on multiple tests in addition to clinical findings before ruling out or diagnosing a disorder (e.g. pulmonary embolism) ${ }^{19}$. On the other hand, the clinicians in Kabul and Phnom Penh were more likely to rely on a single test result to confirm or rule out a diagnosis (e.g. chest $\mathrm{X}$-ray for heart failure or sputum microscopy for tuberculosis). Long-term management with drugs such as statins or angiotensinconverting enzyme (ACE) inhibitors for cardiovascular disease were less frequently used in Phnom Penh and Kabul. This may be due to the higher drug costs and because the benefit from treatment is not immediately apparent to patient and doctor.

Furthermore, not all evidence-based guidelines from North America or Europe may be applicable to developing countries, given that different patient populations are addressed. For example, different outcomes were observed with the use of dexamethasone for bacterial meningitis among adults in Europe ${ }^{6}$, Malawi $^{18}$ and Vietnam ${ }^{14}$.

The trend in clinical decision-making in industrialized nations is to diagnose or rule out an increasing number of causes of medical disorders (e.g. pulmonary embolism in patients with pneumonia or myocardial infarction in patients with cardiac failure $)^{11}$. On the other hand, in the resource-poor setting of both Cambodia and Afghanistan, clinicians were more likely to discontinue a diagnostic work-up after one possible cause was identified. For example, iron-deficiency anemia was explained in terms of poor nutritional intake or hookworm infection and not further investigated for additional causes such as duodenal ulcer or other gastrointestinal disorders.

In conclusion, increased support for healthcare development in developing countries is required from industrialized nations, and mutually beneficial cooperation is possible since similar clinical problems exist on both sides (e.g. HIV or HBV). Examples for possible support of hospital medicine are physician interchange visits with defined objectives (e.g. HIV inpatient care, echocardiography training, gastro-intestinal endoscopy or hospital infection control) and research collaborations (e.g. epidemiology of cardiovascular disease, hospital-acquired bloodborne infections, long-term benefits of aspirin, statins and ACE-inhibitors) that continue locally developed projects.

\section{REFERENCES}

1. Aronson NE, Sanders JW, Moran KA. In harm's way: infections in deployed American military forces. Clinical Infectious Diseases 43:1045-1051, 2006.

2. Bun Navy K, Prem Prey S, Lynen L, Sovanna P, Bell JD, Harwell JI. The first reported cases of disseminated histoplasmosis in Cambodia, complicated by multiple opportunistic infections. Southeast Asian Journal of Tropical Medicine and Public Health 36:1272-1274, 2005.

3. Centers for Disease Control (CDC). Screening for hepatitis B virus infection among refugees arriving in the United States, 1979-1991. Morbidity Mortality Weekly Reports 40:784-786, 1991.

4. Central Intelligence Agency. The world fact book Afghanistan. Accessed online https://www.cia.gov/library/publications/the-world-factbook/geos/af.html December 26, 2007.

5. Chhin S, Rozycki G, Pugatch D, Harwell JI. Aetiology of meningitis in HIV-infected patients in a referral hospital in Phnom Penh, Cambodia. International Journal of sexually transmitted disease and AIDS 15:48-50, 2004.

6. De Gans J, van de Beek D. European Dexamethasone in Adulthood Bacterial Meningitis Study Investigators. Dexamethasone in adults with bacterial meningitis. New England Journal of Medicine 347:1549-1556, 2002. 
7. Department of Health and Human Services (DHHS) Panel on Antiretroviral Guidelines for Adults and Adolescents - A Working Group of the Office of AIDS Research Advisory Council (OARAC). Guidelines for the Use of Antiretroviral Agents in HIV-1-Infected Adults and Adolescents. Rockville, MD: AIDSinfo, 2007.

8. Fransen GA, Janssen MJ, Muris JW, Laheij RJ, Jansen JB. Meta-analysis: the diagnostic value of alarm symptoms for upper gastrointestinal malignancy. Alimentary Pharmacology and Therapeutics 20:1045-1052, 2004.

9. Graybill JR, Sobel J, Saag M, van Der Horst C, Powderly W, Cloud G, Riser L, Hamill R, Dismukes W. Diagnosis and management of increased intracranial pressure in patients with AIDS and cryptococcal meningitis. The NIAID Mycoses Study Group and AIDS Cooperative Treatment Groups. Clinical Infectious Diseases 30: 47-54, 2000.

11. Hilliard AA, Weinberger SE, Tierney Jr LM, Midthun DE, Saint S. Clinical problemsolving. Occam's razor versus Saint's Triad. New England Journal of Medicine 350:599-603, 2004.

12. Hodson EM, Willis NS, Craig JC. Corticosteroid therapy for nephrotic syndrome in children. Cochrane Database Systematic Review 4:CD001533, 2007.

13. Horton R. North and South: bridging the information gap. Lancet 355: 2231-2236, 2000.

14. Nguyen TH, Tran TH, Thwaites G, Ly VC, Dinh XS, Ho Dang TN, Dang QT, Nguyen DP, Nguyen HP, To SD, Nguyen VC, Nguyen MD, Campbell J, Schultsz C, Parry C, Torok ME, White N, Nguyen TC, Tran TH, Stepniewska K, Farrar JJ. Dexamethasone in Vietnamese adolescents and adults with bacterial meningitis. New England Journal of Medicine 357: 2431-2440, 2007.

15. Ni YH, Huang LM, Chang MH, Yen CJ, Lu CY, You SL, Kao JH, Lin YC, Chen HL, Hsu HY, Chen DS. Two decades of universal hepatitis B vaccination in Taiwan: impact and implication for future strategies. Gastroenterology 132: 1287-1293, 2007.

16. Reithinger R, Dujardin JC, Louzir H, Pirmez C, Alexander B, Brooker S. Cutaneous leishmaniasis. Lancet Infectious Disease 7:581-596, 2007.

17. Saag MS, Graybill RJ, Larsen RA, Pappas PG, Perfect JR, Powderly WG, Sobel JD, Dismukes WE. Practice guidelines for the management of cryptococcal meningitis. Clinical of Infectious Diseases 30: 710-718, 2000.

18. Scarborough M, Gordon SB, Whitty CJ, French N, Njalale Y, Chitani A, Peto TE, Lalloo DG, Zijlstra EE. Corticosteroids for bacterial meningitis in adults in subSaharan Africa. New England Journal of Medicine 357: 2441-2450, 2007.

19. Segal JB, Eng J, Tamariz LJ, Bass EB. Review of the evidence on diagnosis of deep venous thrombosis and pulmonary embolism. Annals of Family Medicine 5:63-73, 2007

20. Singh N, Perfect JR. Immune reconstitution syndrome associated with opportunistic mycoses. Lancet Infectious Disease 7:395-401, 2007.

21. Subbaraman R, Chaguturu SK, Mayer KH, Flanigan TP, Kumarasamy N. Adverse effects of highly active antiretroviral therapy in developing countries. Clinical Infectious Diseases 45:1093-1101, 2007.

22. World Health Organization. The world health report 2007 - A safer future: global public health security in the $21^{\text {st }}$ century. World Health Organization Press, Geneva, 2007.

23. Wright P, Inverarity D. Human immunodeficiency virus (HIV) related cryptococcal meningitis in rural central Thailand--treatment difficulties and prevention strategies. Southeast Asian Journal of Tropical Medicine and Public Health 38:58-61, 2007. 